\title{
Environmental Quality Act and Consumer Protection on Inland Water Resources Towards Sustainablity
}

\author{
${ }^{1}$ Muhammad Rizal Razman, ${ }^{2}$ Sakina Shaik Ahmad Yusoff, ${ }^{2}$ Shamsuddin Suhor, \\ ${ }^{2}$ Rahmah Ismail, ${ }^{3}$ Azimon Abdul Aziz and ${ }^{4}$ Kartini Aboo Talib Khalid \\ ${ }^{1}$ Institute for Environment and Development (LESTARI), \\ ${ }^{2}$ Faculty of Law, ${ }^{3}$ Faculty of Economics and Management, \\ ${ }^{4}$ Faculty of Social Sciences and Humanities, \\ Universiti Kebangsaan Malaysia, 43600 UKM Bangi, Selangor, Malaysia
}

\begin{abstract}
The inland water is very precious to every single creature in this world especially to the consumer of the inland water resources. Therefore, it is very vital to take extra care to all of the environmental components which includes the inland water. A good environmental management will ensure the inland water is maintained properly as well as a good protection to the consumer in consuming the inland water. A good environmental management derives from the concept of sustainability. Therefore, this study will examine the used the Environmental Quality Act, 1974 and consumer protection on inland water resources in relation to the sustainability from Malaysian legal perspectives, identify actions and cases which deal with sustainable development from Malaysian legal perspectives and lastly, discussing the regulatory framework as a means for sustainability.
\end{abstract}

Key words: Environmental quality act 1974, consumer protection, inland water resources, sustainability, inland, Malaysia

\section{INTRODUCTION}

Inland water is one of the components in the environment. The inland water is very precious to every single creature in this world (Jahi, 2001; Razman and Azlan, 2009; Razman et al., 2009a) especially to the consumer of the inland water resources. Therefore, it is very vital to take extra care to all of the environmental components which includes the inland water. A good environmental management will ensure the inland water is maintained properly as well as a good protection (Razman et al., 2010a; Sulaiman and Razman, 2010a, b) to the consumer in consuming the inland water. Environmental management can be divided into two parts. The first part is the environmental management through non-legal approaches and the second part is the environmental management through legal means.

The environmental management through non-legal approaches can be done through education, research, monitoring, public policies, guidelines and development plans (Jahi, 2001). On the other hands, the environmental management through legal approaches can done through the implementation of the legislations (Razman et al., 2010b) that being enacted by legislative bodies in the country (Jahi, 2001). Both environmental management the non-legal approaches and the legal approaches derives from the concept of sustainability.

\section{SUSTAINABILITY}

The concept of sustainability has been defined by the World Commission on Environment and Development as development that meets the needs of the present generation without compromising the ability of the future generations to meet their own needs. The above-said concept covers two essential scopes i.e., environment and social aspects. This concept of sustainability has been highlighted in the 1992 United Nations Conference on Sustainable Development in Rio de Janeiro as the results, Agenda 21 and Rio Declaration has been established. According to Sands (1995, 2003), Agenda 21 emphasises the following matters which include sustainable human settlement, population, consumption pattern, poverty and human health. On the other hand, Mensah (1996) stated that the Rio Declaration addresses on mankind entitlements and rights which include health and productive life.

Corresponding Author: Muhammad Rizal Razman, Institute for Environment and Development (LESTARI), Universiti Kebangsaan Malaysia, 43600 UKM Bangi, Selangor, Malaysia 
Basically this concept of sustainability has been an element in the international legal framework since early as 1893. According to the case of United States of America v Great Britain 1 Moore's Int. Arb. Awards 755, well known as Pacific Fur Seals Arbitration where in this case the United States of America has stated that a right to make sure the appropriate and lawful use of seals and to protect them for the benefit of human beings from meaningless destruction (Razman et al., 2009b, 2010c; Emrizal and Razman, 2010).

Sands (1995) indicated that this concept of sustainability is perhaps the greatest contemporary expression of environmental policy, commanding support and presented as a fundamental at the Rio Summit, Rio Declaration on Environment and Development in year 1992.

According to Article 33 of the Lome' Convention 1989 states that in the framework of this Convention, the protection and the enhancement of the environment and natural resources, the halting of deterioration of land and forests, the restoration of ecological balances, the preservation of natural resources and their rational exploitation are basic objectives that the AfricanCaribbean-Pacific (ACP) states concerned shall strive to achieve with Community support with a view to bring an immediate improvement in the living conditions of their populations and to safeguarding those of future generations (Razman et al., 2009c; Emrizal and Razman, 2010; Emrizal et al., 2011).

\section{ENVIRONMENTAL QUALITY ACT, 1974 AND CONSUMER PROTECTION ON INLAND WATER RESOURCES TOWARDS SUSTAINABLITY}

The Environmental Quality Act, 1974 (Act 127) is the primary legal instrument used by the Federal Department of Environment (DOE) in Malaysia to protect the environment. The Environmental Quality Act, 1974 regulates industrial pollution and mitigates environmental impacts of development through many regulations that form the regulatory framework of the act. The act is essentially a pollution prevention law with a focus on managing industrial pollution through licensing with the addition of an Environmental Impact Assessment (EIA) order for the control of development activities. The EIA process is regulated through Federal legislation and associated guidelines-the Environmental Quality (Prescribed Activities) (Environmental Impact Assessment) Order 1987.

However, although, at first blush the punishments under the Environmental Quality Act, 1974 are potentially severe (section 25 provides for RM 100,000 fine and or prison of up to 5 years), conviction under the Act could prove problematic in the absence of a confession or sound environmental baseline information along with strong evidence of actus reus. In order to understand why this is so in the context of inland water resources management for the consumer protection towards sustainability, the relevant provisions of the Environmental Quality Act, 1974 need to be analysed in the context of the definitions for pollutants, pollution and waste.

Section 2 of the Environmental Quality Act, 1974 provide for definitions in which are singularly relevant to interpretation of section 25 restrictions on pollution of inland waters of the Act. The definitions reinforce each other to establish a framework for the prevention of environmental harm especially to rivers. However, they may well be considered to depart from intuitive or common understandings to establish certain clear criteria for determination of whether or not an offence has taken place under the Environmental Quality Act, 1974.

Pollutants is defined as any natural or artificial substances whether in a solid, semi-solid or liquid form or in the form of gas or vapour or in a mixture of at least two of these substances or any objectionable odour or noise or heat emitted, discharged or deposited from any source which can directly or indirectly cause pollution and includes any environmentally hazardous substances.

The definition of pollutants establishes clearly that a pollutant need not be a substance. In this regard, pollutants include but are differentiated from waste which is any matter. Note also that the definition allows for indirect cause of pollution. Although, use of the words indirectly cause might open debate on the nature of an indirect cause, the essence of the concept would seem to broaden the definition to capture pollutants the origin of which might be geographically or temporally distant from any immediate polluting effect. To this extent, the definition supports that of pollution.

Pollution means any direct or indirect alteration of the physical, thermal, chemical or biological properties of any part of the environment by discharging, emitting or depositing environmentally hazardous substances, pollutants or wastes so as to affect any beneficial use adversely to cause a condition which is hazardous or potentially hazardous to public health, safety or welfare or to animals, birds, wildlife, fish or aquatic life or to plants or to cause a contravention of any condition, limitation or restriction to which a license under this Act is subject.

Careful reading of the definition of pollutant (discussed earlier) will reveal that a discharge into the environment is only a pollutant if it causes pollution (including any environmentally hazardous substances). Therefore, the definition of pollution is crucially important to interpretation of relevant sections of the Environmental Quality Act, 1974. 
There are several levels of condition that must be satisfied in order for a discharge to be pollution: firstly, the discharge must alter the physical, thermal, chemical or biological properties of any part of the environment. Furthermore, it must alter any of these properties so as to (emphasis added) affect something or cause change. The definition specifies explicitly the effects or changes that must be caused.

Therefore, for an offence to have occurred not only must the discharge have taken place but an alteration of one of the specified properties must have taken place bringing about one of the detailed effects or changes (notably, one of which can be the contravention of a license condition). Importantly, the definition also lessens the burden of proof by allowing that hazardous substances, pollutants or wastes need only cause a condition that is potentially hazardous thus removing the requirement to prove actual harm to specific organisms, species or habitat in favour of establishing only the potential for such harm to be caused. Nevertheless, the requirement to show that alteration of the environment has taken place would seem to establish a need for comprehensive environmental baseline data to be available.

Waste includes any matter prescribed to be scheduled waste or any matter whether in a solid, semi-solid or liquid form or in the form of gas or vapour which is emitted, discharged or deposited in the environment in such volume, composition or manner as to cause pollution.

The definition of waste provides for matter in any form that is discharged or deposited in the environment in such volume composition or manner as to cause pollution. Therefore, given that pollution requires an alteration of the environment so as to affect something or cause change (specified in the definition), until some given matter (excluding prescribed scheduled waste) has such effect or causes such change, it is not waste. Under such a definition, many discrete discharges of small quantities of a matter, any one of which in isolation fails to satisfy the definition of waste or pollution would seem potentially to be problematic under the Act.

On balance, section 25 (restrictions on pollution of inland waters) is probably the most powerful legislative tool available to protect the quality of river water. The section is quite brief but embraces some interesting concepts. A weakness of the section is that it refers to environmentally hazardous substances, pollutants or waste and the last of these terms are defined in section 2 in such a way as practically to exclude the discharge of small amounts of matter or discharges that fail to affect or cause the stipulated change or outcome. The first two paragraphs in particular merit detailed discussion.

Section 25 (1) stated that no person shall, unless licensed, emit, discharge or deposit any environmentally hazardous substances, pollutants or wastes into any inland waters in contravention of the acceptable conditions specified under section 21 .

Read in isolation of subsection (2) of section 25 , subsection (1) would do little to protect inland waters. For an offence to occur, sufficient quantity of the discharged matter or pollutant must enter into the inland waters in contravention of the acceptable conditions specified under section 21. Also, the chosen verbs: emit, discharge or deposit would seem to require proof of an act of discharge which in turn might imply the necessity to prove intent. However, subsection (2) provides for a person to be deemed to emit, discharge or deposit in a manner that goes somewhat beyond a literal meaning of these verbs and that establishes clear grounds to support an offence caused through negligence.

As for section 25 (2) highlighted that without limiting the generality of subsection (1), a person shall be deemed to emit, discharge or deposit wastes into inland waters if:

- He places any wastes in or on any waters or in a place where it may gain access to any waters

- He places any waste in a position where it falls, descends, drains, evaporates is washed is blown or percolates or is likely to fall, descend, drain, evaporate or be washed be blown or percolated into any waters or knowingly or through his negligence whether directly or indirectly, causes or permits any wastes to be placed in such a position

- He causes the temperature of the receiving waters to be raised or lowered by more than the prescribed limits

Subsection (2) of section 25 tightens the provision considerably to recognise that a person can emit, discharge or deposit" waste even if the waste is placed at a location where it simply has the potential to gain access to any waters. The subsection anticipates a defence based on an act of nature to specify that any form of transmittal of the waste into waters including means of transmittal associated with rain, wind, seepage, leakage, misadventure and condensation would still constitute an emission, discharge or deposit of the waste for the purpose of the Act. Subparagraph (b) specifically provides for an offence caused through an act of negligence and in doing so provides a foundation to argue the requirement for due diligence and reasonable 
care. Although, section 25 potentially is limited in application by the various thresholds established in the definitions of pollution, pollutant and waste, the provisions of subsection (2) are still far-reaching and important. If applied to the extent that the Act would appear to allow, section 25 would be adequate to punish and therefore dissuade gross pollution of inland waters.

The Environmental Quality (Sewage) Regulations, 2009 and Environmental Quality (Industrial Effluents) Regulations, 2009 outline parameters and their associated effluent standards for industrial and development projects. It specifies one set of values for projects within catchments (areas upstream of surface or above ground water supply intakes for the purpose of consumer consumption including drinking) and one for all other areas. Project operators may exceed the emission or effluent standards subject to being granted a licence from the Department of Environment to do so.

In the main, the Environmental Quality Act, 1974 is concerned with control of pollution and remains silent on some important environmental questions such as biological diversity preservation and habitat protection and restoration (Sharom, 1998). Importantly, the Act recognises that some activities will need to pollute and seeks to control but not prevent these activities through a system of licensing. Pollution of inland waters without a license to do so is an offence under section 25 (as discussed above). Section 21 provides for acceptable conditions for discharge of pollution, as determined by the Minister in consultation with the Council. Implementation of such acceptable conditions might assist in ensuring effective implementation and enforcement of those relevant provisions.

\section{CONCLUSION}

This study suggests that the Environmental Quality Act, 1974 promotes the concept of sustainablity in order to prevent pollution to inland water resources. In this manner, the above-mentioned legislation in a way also try to protect consumer that consumed water from inland water resources in Malaysia.

\section{ACKNOWLEDGEMENT}

This study was conducted by using the research funding of the UKM-AP-CMNB-02-2010 project.

\section{REFERENCES}

Emrizal and M.R. Razman, 2010. The study on international environmental law and governance: Focusing on the montreal protocol and the role of transboundary liability principle. The Social Sci., 5: 219-223.
Emrizal, M.R. Razman and J.M. Jahi, 2011. Study on human habitat and environmental protection: Focusing on the criminal law and the concept of sustainability. Res. J. Applied Sci., 6: 10-14.

Jahi, J.M., 2001. Environment, environmental management and quality of life in Malaysia. Paper Presented at the SEAGA 6, 2001 International Conference on Southeast Asia's Quality of Life in the New Millennium, 12-15 November 2001, Universiti Kebangsaan Malaysia, Bangi.

Mensah, C., 1996. The United Nations Commission on Sustainable Development. In: Greening International Institutions, Werksman, J. (Ed.). Earthscan, London, pp: 21-37.

Razman, M.R. and A. Azlan, 2009. Safety issues related to polychlorinated dibenzo-p-dioxins (PCDDs) and polychlorinated dibenzofurans (PCDFs) in fish and shellfish in relation with current Malaysian laws. J. Food Agric. Environ., 7: 134-138.

Razman, M.R., A. Azlan, J.M. Jahi, K. Arifin, K. Aiyub, A. Awang and Z.M. Lukman, 2010a. Consumer protection on food and environmental safety based on statutory implied terms in Malaysian sale of goods law: Focusing on urban sustainability. Int. Bus. Manage., 4: 134-138.

Razman, M.R., A. Azlan, J.M. Jahi, K. Arifin, K. Aiyub, A. Awang and Z.M. Lukman, 2010b. Urban sustainability and Malaysian laws on environmental management of chemical substances. Res. J. Applied Sci., 5: 172-176.

Razman, M.R., A.S. Hadi, J.M. Jahi, A.H.H. Shah and A.F. Mohamed et al., 2009a. The international law mechanisms to protect human habitat and environment: Focusing on the principle of transboundary liability. Int. Bus. Manage., 3: 43-46.

Razman, M.R., A.S. Hadi, J.M. Jahi, A.H.H. Shah, S. Sani and G. Yusoff, 2009c. A study on negotiations of the montreal protocol: Focusing on global environmental governance specifically on global forum of the United Nations environmental programme. J. Food Agric. Environ., 7: 832-836.

Razman, M.R., A.S. Hadi, J.M. Jahi, A.H.H. Shah, S. Sani and G. Yusoff, 2010c. A study on the precautionary principle by using interest approach in the negotiations of the montreal protocol focusing on international environmental governance and law. J. Food Agric. Environ., 8: 372-377.

Razman, M.R., A.S. Hadi, J.M. Jahi, K. Arifin and $\mathrm{K}$. Aiyub et al., 2009b. The legal approach on occupational safety, health and environmental management: Focusing on the law of private nuisance and International Labour Organisation (ILO) decent work agenda. Int. Bus. Manage., 3: $47-53$. 
Sands, P., 1995. Principles of Global Environmental Law I: Frameworks, Standards and Implementation. 1st Edn., Manchester University Press, Manchester, UK., ISBN: 0-7190-3484-1.

Sands, P., 2003. Principles of International Environmental Law. Cambridge University Press, Cambridge.

Sharom, A., 1998. Understanding the Environmental Quality Act 1974. In: Current Legal Problems in Malaysia, Majid, M.K. (Ed.). University of Malaya Press, Kuala Lumpur.
Sulaiman, A. and M.R. Razman, 2010a. A comparative study on the international and islamic law: Focusing on the transboundary liability and trespass for better living environment in urban region. The Social. Sci., 5: 213-218.

Sulaiman, A. and M.R. Razman, 2010b. Study on international environmental law and governance: Focusing on basel convention and role of precautionary principle. J. Food Agric. Environ., 8: 1216-1219. 